\title{
New perspectives on the role of Escherichia coli 0157:H7 and other enterohaemorrhagic $E$. coli serotypes in human disease
}

\author{
P. N. GOLDWATER and K. A. BETTELHEIM*
}

Microbiology and Infectious Diseases Department, Women's and Children's Hospital, North Adelaide, South Australia 5006 and *National Escherichia coli Reference Laboratory, Victorian Infectious Diseases Reference Laboratory, Fairfield, Victoria, Australia

\begin{abstract}
This review compares the rates of detection of non-0157:H7 enterohaemorrhagic Escherichia coli (EHEC) with EHEC 0157:H7 in outbreaks and sporadic cases of human disease by analysing Australian data and the world literature. Numerous outbreaks of disease have been attributed to EHEC 0157:H7. In many studies, isolation rates of this organism have been low and attempts to seek other EHEC have not been made. Ease of isolation and identification of the 0157:H7 serotype may have given the impression that this serotype was the sole organism responsible for the outbreaks. Careful review and analysis shows that serotypes other than 0157:H7 also play an important role in human disease. Evidence is presented from several overseas outbreaks described in the literature, as well as from investigations of the Adelaide O111: $\mathrm{H}^{-}$ outbreak, that suggests an association between severity of disease and multiple infecting serotypes. While not diminishing the role of the $0157: \mathrm{H} 7 / \mathrm{H}^{-}$clone, this review indicates that other serotypes can be responsible for outbreaks as well as cases of sporadic human disease. The current focus on 0157:H7 has major implications in terms of diagnosis, the food industry and human health.
\end{abstract}

\section{Introduction}

From the first description 15 years ago [1] of outbreaks of disease caused by enterohaemorrhagic Escherichia coli (EHEC) O157:H7, this serotype has tended to dominate the world literature on EHEC. Evidence suggests that EHEC O157:H7 isolates are derived from one particularly successful clone of $E$. coli that has spread around the world. Long before the emergence of this strain, and ever since, there have been reports of human cases and outbreaks of disease caused by serotypes of $E$. coli other than O157:H7. On occasion, these may occur concomitantly with O157:H7 cases, which may lead to the false labelling of an outbreak as one caused by this serotype only.

Investigation of the Adelaide haemolytic uraemic syndrome (HUS) outbreak has provided several insights into the epidemiology of EHEC. Polymerase chain reaction (PCR) detection of $E$. coli stx genes

Received 19 Dec. 1997; revised version received 19 May 1998; accepted 26 May 1998.

Corresponding author: Dr P. N. Goldwater. had been introduced as part of research into sudden infant death syndrome. It was fortuitous that the PCR assay was available at the time of the epidemic as it allowed detection of EHEC O111: $\mathrm{H}^{-}$. The hospital laboratory had not introduced selective media for the isolation of $E$. coli $\mathrm{O} 157: \mathrm{H} 7$, but such an approach, without PCR detection of stx genes, would have failed to detect $E$. coli $\mathrm{O} 111: \mathrm{H}^{-}$. The examination in a different laboratory of a faecal specimen from one of the Adelaide HUS cases, who was hospitalised interstate, and the detection in that specimen of a number of EHEC serogroups including 0111 and O157, alerted the epidemic investigation to the simultaneous presence of the O157 clone, which was found subsequently in two other patients [2]. Examination of reports of outbreaks of EHEC-related disease indicates that most have been under-investigated from the point of view of the possible involvement of multiple serotypes of E. coli. This review provides a fresh look at the epidemiology of $E$. coli and raises issues important to our understanding of why some epidemics are mild clinically and others severe. In addition, the review illustrates some of the important issues involved in the microbiology of foodborne E. coli disease. 
Isolation rates and outbreaks of disease caused by 0157:H7 and other EHEC

A Medline review of the literature was performed to ascertain the detection rate of $E$. coli $0157: \mathrm{H} 7$ compared with other EHEC serotypes in outbreaks of bloody diarrhoea (BD) associated with HUS. The published data from the reported outbreaks of EHEC disease were then analysed to determine the rate at which O157:H7 and non-O157 serotypes were detected. Table $1[1,3-23]$ shows the isolation rate of EHEC O157:H7 in published studies of outbreaks attributed to this serotype. Specific comment in regard to the manner of investigation, conclusions drawn in regard to the findings and our re-interpretation of the data of many of these cited studies is provided below. Table 2 [2, 24-31] provides data on seven documented outbreaks attributed to EHEC serogroup O111. Isolates from the Adelaide $\mathrm{O} 111: \mathrm{H}^{-}$epidemic $[2,32]$ included EHECs other than $0111: \mathrm{H}^{-}$, and included isolates of $\mathrm{O} 157: \mathrm{H} 7$ or $\mathrm{O} 157: \mathrm{H}^{-}$from three patients. Two of these patients were reported separately [33] and also in the State Coroner's Report. Other Shiga-toxin-producing $E$. coli (STEC) serotypes including O111:H7 [32] (subsequently shown to be serotype O111:H8; personal unpublished results) were isolated from patients, and STEC serogroups O113, O82(:H8), O91, O98, O159 and $\mathrm{O} 157$ were isolated, in addition to serotype $0111: \mathrm{H}^{-}$, from the incriminated food source of mettwurst fermented sausage [32].

Data published previously $[34,35]$ on serotypes causing disease in Australia show a wide spectrum of serotypes, including a number that had not been found elsewhere at the time. Many have since been described in other parts of the world. Table 3 $[26,34,36-45]$ shows data attributed to non-O157 and non-O111 EHEC outbreaks and sporadic cases of disease. Included in this table are outbreaks of disease attributed to enteropathogenic E. coli (EPEC) O111: B4 in the middle of this century $[30,31]$. The clinical features described in the 1953 USA outbreak [31] (diarrhoea, bloody stools, renal failure and anuria, skin petechiae, seizures, ileus, gut infarcts, shock, coma and death) are suggestive of HUS and indicate that these isolates could have carried stx genes. A proportion of classical EPEC strains have been shown on retrospective analysis to carry such genes [46].

\section{Detailed analysis of outbreak reports}

It is manifest from the numerous reports of outbreaks attributed to EHEC O157:H7 that this serotype can at best account for only $60 \%$ of isolates in such outbreaks. The study by Pavia et al. [3] found only 16 cases $(10 \%)$ with $\mathrm{O} 157: \mathrm{H} 7$ out of a total of 157 , yet the epidemic was attributed to $0157: \mathrm{H} 7$ as the sole causal EHEC. It is noteworthy that the proportion of cases with serogroup $\mathrm{O} 157$ infection detected in that outbreak was similar to that of the Adelaide $0111: \mathrm{H}^{-}$ epidemic. Furthermore, most studies appear to have neglected non-O157:H7 EHEC during the investigation of the outbreak. This is illustrated by the remainder of this section which considers the methodology used for the investigation of individual outbreaks.

Table 1. Outbreaks of disease attributed to EHEC O157:H7 and its rate of isolation

\begin{tabular}{|c|c|c|c|c|}
\hline \multicolumn{3}{|c|}{ Cases of HUS or BD } & \multirow[b]{2}{*}{ Reference } & \multirow[b]{2}{*}{ Country } \\
\hline $\begin{array}{l}\text { Number } \\
\text { investigated }\end{array}$ & $\begin{array}{l}\text { Number }(\%) \\
\text { yielding } 0157\end{array}$ & $\begin{array}{c}\text { Number }(\%) \\
\text { yielding non-O157 }\end{array}$ & & \\
\hline 157 & $16(10)$ & $?$ & {$[3]$} & USA \\
\hline 39 & $8(21)$ & $?$ & {$[4]$} & Germany \\
\hline 269 & $59(22)$ & $3(1.1)$ & [5] & UK \\
\hline 174 & $42(24)$ & $? 66(37.9)^{*}$ & [6] & Japan \\
\hline 647 & $161(25)$ & $?$ & [7] & UK \\
\hline 54 & $15(28)$ & $?$ & [8] & USA \\
\hline 36 & $21(58)$ & $?$ & [9] & USA \\
\hline 521 & $152(29)$ & $?$ & [10] & Canada \\
\hline 28 & $8(29)$ & $?$ & [11] & USA \\
\hline 70 & $24(34)$ & $?$ & [12] & Canada \\
\hline 23 & $8(35)$ & $?$ & [13] & USA \\
\hline 37 & $14(38)$ & $?$ & [14] & USA \\
\hline 14 & $6(43)$ & $?$ & [1] & USA \\
\hline 32 & $14(44)$ & $?$ & [15] & USA \\
\hline 24 & $12(50)$ & $?$ & [16] & USA \\
\hline 10 & $5(50)$ & ? & [17] & USA \\
\hline 6 & $3(50)$ & $?$ & [18] & Australia \\
\hline 6 & $3(50)$ & $4(66.6)^{\dagger}$ & [19] & Czech Rep \\
\hline 6 & $3(50)$ & $?$ & {$[1]$} & USA \\
\hline 11 & $6(55)$ & $5(45.5)$ & [20] & USA \\
\hline 23 & $13(57)$ & $?$ & [21] & UK \\
\hline 12 & $7(58)$ & $?$ & [22] & USA \\
\hline 30 & $18(60)$ & $5(16.6)$ & [23] & Germany \\
\hline
\end{tabular}

HUS, haemolytic uraemic syndrome; BD, bloody diarrhoea.

* Of 108 cases, 66 yielded 'pathogenic' $E$. coli not otherwise defined.

${ }^{\dagger}$ Serogroups identified were O1, O5, O18 and O26. 
Table 2. Reported outbreaks of EHEC O111

\begin{tabular}{|c|c|c|c|c|c|}
\hline Serotype & Year & Country [ref.] & Setting & $\begin{array}{l}\text { Number of } \\
\text { cases in } \\
\text { outbreak* }\end{array}$ & Source \\
\hline \multicolumn{6}{|c|}{ Recognised EHEC O111 outbreaks: } \\
\hline 1. $0111: \mathrm{H}^{-}$ & 1986 & Japan [24] & Orphanage & 22 & Unknown \\
\hline 2. $0111: \mathrm{H} 2$ & 1988 & Australia [25] & Family & 5 & Unknown \\
\hline 3. $0111: \mathrm{H}^{-}$ & 1991 & Japan [26] & Primary school & 234 & Unknown \\
\hline 4. $\mathrm{O} 111: \mathrm{H}^{-}$ & 1992 & Italy [27] & Community & 9 & Unknown \\
\hline 5. $\mathrm{O} 111: \mathrm{B} 4$ & 1992 & France [28] & Primary school & 26 & Unknown \\
\hline 6. $0111: \mathrm{H}^{-}$ & 1995 & Australia [2] & Community & $23 /\left(>141^{\dagger}\right)$ & Mettwurst \\
\hline 7. $\mathrm{O} 111: \mathrm{H}^{-}$ & 1996 & USA [29] & Family & 5 & Unknown \\
\hline \multicolumn{6}{|c|}{ Possible EHEC O111 outbreaks: } \\
\hline 8. $0111: B 4$ & 1947 & Scotland [30] & Nursery & 417 & Unknown \\
\hline 9. $0111: B 4$ & 1953 & USA [31] & Nursery & $\begin{array}{l}143 \text { Outpatients } \\
49 \text { Inpatients }\end{array}$ & Nosocomial \\
\hline
\end{tabular}

${ }^{*}$ Sporadic cases of $\mathrm{HC}$ or HUS associated with $\mathrm{O} 111: \mathrm{H}^{-}$have also been reported from Belgium, Germany, Austria and the Czech Republic. There were 23 cases of HUS, but more cases of diarrhoea and BD were detected following the cited publication that mentioned 141 cases (personal unpublished data).

Table 3. Outbreaks and sporadic disease caused by non-O157:H7 and non-O111 enterohaemorrhagic E. coli

\begin{tabular}{|c|c|c|c|c|c|c|}
\hline Serotype & Year & Place & Setting & $\begin{array}{l}\text { Number } \\
\text { of cases }\end{array}$ & Source & Reference \\
\hline $\mathrm{O} 26$ & 1979 & UK & $\mathrm{BD} ;$ sporadic/community & 3 & Unknown & [36] \\
\hline $\mathrm{O} 26: \mathrm{H}^{-}$ & $1989-91$ & UK & $\mathrm{HC} / \mathrm{HUS}$ & $\ldots$ & Unknown & [37] \\
\hline $\mathrm{O} 26: \mathrm{H} 11$ & $1987-90$ & Germany & & $\ldots$ & Unknown & [38] \\
\hline $\mathrm{O} 26: \mathrm{H} 11$ & $1984-93$ & Japan & Sporadic/intrafamilial & 16 & Unknown & [39] \\
\hline $\mathrm{O} 26: \mathrm{H} 11$ & $1978-79$ & New Zealand & Diarrhoea & $\ldots$ & Unknown & [40] \\
\hline O26:H11 & 1992 & Australia & HUS & 1 & Unknown & [34] \\
\hline $\mathrm{O} 26: \mathrm{H} 11$ & $1988-95$ & Czech Rep. & HUS & 5 & Unknown & [41] \\
\hline $\mathrm{O} 91: \mathrm{H} 21$ & $1987-90$ & Germany & HUS & $\ldots$ & Unknown & [38] \\
\hline $\mathrm{O} 103: \mathrm{H} 2$ & $1987-89$ & France, & HUS & 6 & Unknown & [42] \\
\hline $\mathrm{O} 103: \mathrm{H} 2$ & & USA & Urinary infection & 1 & Unknown & [43] \\
\hline $\mathrm{O} 104: \mathrm{H}_{2} 1$ & 1994 & USA (Montana) & Outbreak/gastroenteritis & 17 & Unknown & [44] \\
\hline $\mathrm{O} 113: \mathrm{H} 21$ & 1997 & Australia & BD TTP & 1 & Unknown & {$[51]$} \\
\hline $\mathrm{O} 145: \mathrm{H}^{-}$ & 1984 & Japan & Diarrhoea & 100 & Unknown & [39] \\
\hline Ont:H19 & 1991 & Japan & School & 89 & Unknown & {$[26,39]$} \\
\hline Ont:H19 & $1984-93$ & Japan & $?$ & 1 & Unknown & [39] \\
\hline 0165 & 1995 & Japan & $?$ & 4 & Unknown & {$[45]$} \\
\hline
\end{tabular}

$\mathrm{BD}$, bloody diarrhoea; TTP, thrombotic thrombocytopenic purpura; HUS, haemolytic uraemic syndrome.

In the Utah, USA, outbreak [3] of diarrhoea, BD and HUS in two institutions for the mentally retarded, sorbitol-MacConkey agar culture (SMAC) was used to recognise non-sorbitol fermenting (NSF) colonies. Other EHEC would not have been selected. The presence of EHEC O157:H7 was confirmed by culture in 16 patients $(10.2 \%)$, although specimens from 157 patients were examined. In a child care centre in Germany there was an outbreak of diarrhoea and BD in three waves during the summer [4]. Of 39 persons affected, 32 were children at the centre; five further children were contacts and there were also two adults. With a dot-blot ELISA for detecting toxins SLT-I and II from colonies growing on MacConkey agar plates, E. coli $\mathrm{O} 157: \mathrm{H} 7$ was identified from the first case. All subsequent plates were screened only with anti-O157 serum by slide agglutination. Ten $(25.6 \%)$ of the 39 patients yielded $\mathrm{O} 157$ strains. The review by Thomas et al. [5] of 1468 cases with evidence of infection showed that 1266 had $E$. coli $\mathrm{O} 157: \mathrm{H} 7$ by isolation of the organism. It is not clear how detailed the investigations were, but only confirmed EHEC O157:H7 isolates were studied in an unstated number of cases.
Nevertheless, 13 different non-O157 verotoxigenic isolates (VTEC) were found. Two patients had different VTEC (O157:H7 and O173:H2; and $\mathrm{O} 9: \mathrm{H}^{-}$and $\left.\mathrm{O} 101: \mathrm{H}^{-}\right)$.

An outbreak in a nursery school in Japan in late summer to autumn was described by Akashi et al. [6]. Of 174 patients examined, there were 101 cases of diarrhoea and 20 cases of HUS; 53 patients were symptom-free. SMAC was used to identify VTEC. From 101 diarrhoea cases, EHEC 0157:H7 was isolated from $21(20.8 \%)$. From 20 cases of HUS, EHEC O157:H7 was isolated from 14 cases $(70 \%)$, and it was also isolated from seven $(13.2 \%)$ of 53 symptomless patients. Chapman and Siddons [7] reported a study designed to determine the value of specific methods for isolation of $E$. coli $\mathrm{O} 157: \mathrm{H} 7$ from faeces. From 272 cases of BD, 375 of diarrhoea, 19 follow-up and 24 contacts (total 690), a maximum of 25 cases $(3.6 \%)$ was found to be positive for $E$. coli $\mathrm{O} 157: \mathrm{H7}$. An outbreak of VTEC disease (diarrhoea and BD) in Minnesota, USA, in a junior high school was reported by Belongia et al. [8]. Only 
SMAC was used to detect VTEC. There were 31 cases of BD of which $14(45.2 \%)$ yielded VTEC O157:H7 and 23 cases of diarrhoea in which one $(4.3 \%)$ yielded VTEC O157:H7. While meat patties were incriminated on epidemiological grounds, VTEC O157:H7 could not be isolated from uneaten patties. Again, only SMAC was used for detection of NSF colonies.

An outbreak in a small town in Missouri from Dec. 1989 to Jan. 1990, in which 243 people were affected, was described by Swerdlow et al. [9]. In total, 86 patients had $\mathrm{BD}$ and the remaining 157 had diarrhoea. SMAC was used to isolate EHEC O157:H7, which was found in $18(76 \%)$ of 25 patients with $\mathrm{BD}$ and from two $(28.6 \%)$ of seven patients with diarrhoea. Although the water supply was incriminated on epidemiological evidence, no VTEC was isolated from the water. Another outbreak involving six Canadian Arctic communities occurred between June and Oct. 1991 [10] in which 521 individuals developed diarrhoea, including 103 with BD. Although SMAC was used to isolate VTEC, verotoxin (VT) was looked for in polymyxin extracts of colony sweeps and in faecal extracts, and 129 patients $(24.8 \%)$ were confirmed by culture to be positive for EHEC O157:H7. In another outbreak following a banquet involving 226 people, 61 of 193 persons interviewed reported illness [11]. The authors noted the remarkably benign clinical course of the illness. Stool specimens from 28 symptomatic patients were tested by SMAC for VTEC and eight $(28.6 \%)$ yielded EHEC O157:H7. In addition, cultures from three $(8 \%)$ of 37 asymptomatic attendees yielded this organism. E. coli $\mathrm{O} 157: \mathrm{H} 7$ was isolated from a sample of the same batch of beef that was used in the banquet. In a nursing home in Ontario, Canada, in Sept. 1985, 55 residents and 18 staff (total 73) had diarrhoea or BD. SMAC was used to investigate the outbreak, and yielded EHEC 0157:H7 from 24 $(34.3 \%)$ of 70 symptomatic cases and one $(2.7 \%)$ of 37 asymptomatic individuals. Free faecal VT was present in $23(50 \%)$ of 45 symptomatic and in none of six asymptomatic cases. The difference between the detection rate for VT and O157:H7 isolation could be explained by the presence of non-O157 STEC that would not be recognised with SMAC. In another nursing home outbreak in Washington State, USA, during Oct.-Nov. 1986, there were 37 cases of which $14(37.8 \%)$ yielded E. coli $0157: \mathrm{H} 7$ on SMAC. Another outbreak at a nearby nursing home was also reported, but cases were defined only on the basis of culture of E. coli $\mathrm{O} 157: \mathrm{H7}$, thus limiting the range of possible EHEC to only one.

The report of Riley et al. [1], which was the first to alert scientists to O157 VTEC, describes two outbreaks in 1982. No selective media were used and five E. coli colonies from each faecal specimen were examined and serotyped. E. coli $\mathrm{O} 157: \mathrm{H} 7$, as well as Bacillus pumilis and Klebsiella oxytoca, were the only bacteria isolated from three or more cases in either outbreak. In Oregon, E. coli O157:H7 was isolated from three $(50 \%)$ of six specimens and no controls, and from $\operatorname{six}(43 \%)$ of 14 specimens in Michigan. Subsequently, the review by Griffin et al. [15] examined a number of outbreaks in the USA and Canada, focusing on E. coli $\mathrm{O} 157: \mathrm{H7}$, and recommended the use of SMAC for its isolation.

The June 1995 Colorado child care outbreak [16] involving 141 children, including 24 cases of diarrhoea and $\mathrm{BD}$, yielded E. coli $\mathrm{O} 157: \mathrm{H} 7$ from 12 cases $(50 \%)$. The authors failed to describe the method of isolation, but as no other $E$. coli was mentioned, it is assumed that an O157-specific technique was used. One reason frequently given to explain the lack of isolation of $E$. coli $\mathrm{O} 157: \mathrm{H} 7$ is the very rapid clearing of the organism from the gut and the fact that isolation of the organism is unlikely after the first week of symptoms. In this outbreak it was noted that the duration of shedding had a range of 11-57 days with a mean of 29 days.

In the Sept. 1993 Connecticut, USA, outbreak among picnic attendees [17], 23 persons met the case definition, of whom 10 had stools cultured with five (50\%) positive for E. coli O157:H7. All positive individuals had BD. Incriminated meat patties also yielded E. coli $\mathrm{O} 157: \mathrm{H} 7$. It is interesting to note that the laboratory had begun screening for E. coli $\mathrm{O} 157$ only in June of that year.

The outbreak in March 1996 in south Queensland, Australia [18] was labelled as having been caused by E. coli $\mathrm{O} 157$ on the basis of SMAC. Disease was mild in this outbreak and 57 people provided 84 faecal specimens. Six people were infected with O157, including three patients, an asymptomatic relative and two food handlers. Twenty-one other associated people, including two patients and six family contacts, were negative for $\mathrm{O} 157$, as were 30 people used as controls. Thus $\mathrm{O} 157$ was isolated from three $(60 \%)$ of five patients or, overall, from six $(22.2 \%)$ of 27 patients, contacts and suspect food handlers.

In an outbreak in northern Bohemia in 1988 [19], there were five cases of HUS and one case of $\mathrm{HC}$. Two of the HUS cases and the $\mathrm{HC}$ case yielded O157:H7, while two others yielded EHEC O26 and one case yielded STEC O1. One of the HUS cases with O157 also had STEC O5. SMAC was used in conjunction with specific tests to select non-O157 STEC.

In the June-Nov. 1995 New York hospital study [20], 270 stool specimens described as having the following characteristics: 'liquid, semiliquid, mucous, blood, ...' were tested with SMAC and the Meridian EHEC test kit. Of the 270 specimens, 11 were positive for SLT and six $(54.5 \%)$ of these were positive for $\mathrm{O} 157: \mathrm{H} 7$. Other serotypes isolated were $\mathrm{O} 88: \mathrm{H}^{-}, \mathrm{O} 103: \mathrm{H}^{-}$, 
O111: $\mathrm{H}^{-}$and $\mathrm{OR}: \mathrm{H}^{-}(\times 2)$. This study suggests that non-O157:H7 serotypes also play a role in disease in the USA but, as indicated from the studies cited in Table 1, if other serotypes are not sought, they will not be found! Karch et al. [23] used SMAC, cefiximetellurite SMAC (CT-SMAC) and DNA-based methods to identify VTEC in 30 cases of sporadic HUS from Germany collected between March and Aug. 1995. Eighteen cases $(60 \%)$ yielded strains of 0157 and five $(16.7 \%)$ yielded non-O157 EHEC. The latter included $\mathrm{O} 2: \mathrm{H} 6, \mathrm{O} 8: \mathrm{H} 21, \mathrm{O} 26: \mathrm{H}^{-}, \mathrm{O} 69: \mathrm{H}^{-}$and $\mathrm{O} 111: \mathrm{H}^{-}$, indicating that where other serotypes are sought they will be found. It is noteworthy that of these five nonO157 EHEC, two $\left(\mathrm{O} 26: \mathrm{H}^{-}\right.$and $\left.\mathrm{O} 111: \mathrm{H}^{-}\right)$have been isolated in other outbreaks (Tables 2 and 3 ).

The christening party outbreak of diarrhoea and $\mathrm{HC}$ affecting 26 of 93 people and resulting in one case of HUS [21] was investigated by SMAC. Faeces from 23 cases and 33 asymptomatic guests were cultured on SMAC and colonies tested for the stxl and stx 2 genes by PCR. Of 23 cases examined, $13(56.5 \%)$ were O157 positive and three $(9.1 \%)$ of 33 asymptomatic guests were $\mathrm{O} 157$ positive. It is not clear from the description of the methods which colonies were tested by PCR, but if only sorbitol-negative colonies were tested then this would limit the possibilities for nonO157 STEC isolation.

The investigation of several outbreaks has also been biased by limiting the case definition to positive 0157:H7 culture or serology. The outbreak of diarroea, $\mathrm{HC}$ and HUS associated with bathing in a lake in Illinois, USA, serves to illustrate this point [22]. In the investigation, 12 cases were identified, of which seven $(58.3 \%)$ were positive for EHEC $0157: \mathrm{H} 7$ by culture, yet the culture method was not disclosed. Case definition was based on culture of EHEC O157:H7 or a positive serological reaction for the O157 serogroup, or both. Therefore, it would seem that other serotypes were not sought.

Returning to the Adelaide HUS epidemic of summer 1995, had there been no system available for detecting O111 then this outbreak, like most of the abovementioned outbreaks, would almost certainly have been attributed to EHEC O157, which was found in three patients [33]. It follows that if the majority of outbreaks have had their investigations limited to EHEC O157:H7, then it is plausible that certain clinical parameters associated with EHEC may have been misrepresented. For instance, clinical severity in relation to apparent single agent versus mixed EHEC infection may be important. The study by Rodrigue et al. [11] drew attention to the benign clinical course. Could this and other clinically mild outbreaks [18] have been caused by EHEC 0157:H7 alone? That is, a 'single agent' outbreak accounting for the benign clinical features. On the other hand, could severe outbreaks, with relatively large numbers of cases of
HUS, such as occurred in the Adelaide epidemic, be the result of multiple strains acting 'in concert'? Our serological analysis of the Adelaide outbreak has shown significant antibody responses to a much wider range of $E$. coli serotypes than was found in the patients or the incriminated food source of fermented sausage (mettwurst) (personal unpublished observations). Until such time when outbreaks are investigated for all possible EHEC, the answer to the above question with regard to possible clinical correlations between severity of disease and numbers of infecting serotypes (and hence, possibly, Shiga toxin types) will remain unanswered. Furthermore, this work has been confounded by the absence of an animal model that accurately reflects the mechanisms of colonisation and pathogenesis of disease in man. Recently, Pierard et al. [47] screened over 17000 faeces submitted for routine culture for VTEC and showed that cases of HUS were observed only in association with EHEC 0157:H7. Seventeen of 21 Adelaide epidemic HUS patients had antibody to serogroup O157, while this serogroup was found in only two of these patients' faeces (personal unpublished observations). Therefore, these serological data support the pathogenic role of EHEC O157; however, on the other hand, there was no difference between the number of patients with antibody to this serogroup who had complications of HUS (chronic renal failure, infarcts, etc.) and the number of $\mathrm{O} 157$ seropositive patients without complications. Therefore, the role of 0157 infection in disease severity needs further study, as does the number of infecting EHEC serotypes per patient.

\section{Conclusions}

While not diminishing the role of the O157:H7 clone, this review illustrates the importance of recognising that other serotypes are responsible for outbreaks as well as cases of sporadic human disease. It is also apparent from the literature that a wide variety of EHEC impinge on the human host from a wide range of food and non-food sources. Failure to identify the source is not uncommon. On the basis of this review, it is clear that non-O157:H7 are important (and probably underestimated) causes of disease. Clearly, other EHEC will be missed unless they are looked for specifically with a 'broad brush' approach (e.g., PCR detection of stx genes [32] or direct detection of toxins [48] in faeces or faecal cultures). Medical diagnostic and public health laboratories should be encouraged to use techniques that detect stx genes or toxins in clinically and epidemiologically appropriate specimens, and should not restrict themselves to looking for O157:H7. The current focus on EHEC O157:H7, and seeming neglect of other EHEC, has major implications in terms of diagnosis, the food industry and human health. In addition, the practice of some authors of implying that EHEC $0157: \mathrm{H} 7$ is part of the definition of HUS should be discouraged. Ignoring the well- 
established data presented in this review that EHEC other than O157:H7 also cause HUS is clearly counterproductive and potentially dangerous.

With the USA and northern hemisphere countries continuing to focus on serotype O157:H7, as evidenced by its inclusion in the list of notifiable diseases issued by the Centers for Disease Control and Prevention [49], further effort will be required to encourage laboratories to look beyond this serotype. Nevertheless, the recent WHO consultation on the prevention and control of EHEC infections held in Geneva (28 April-1 May 1997) [50] seems to have gone some way toward recognising the problem of this restrictive approach to diagnosis of EHEC-related diseases. On the same basis, the food industry should also be encouraged to follow this line by being cognisant with the importance of non-O157:H7 EHEC as well as $\mathrm{O} 157: \mathrm{H} 7$.

\section{References}

1. Riley LW, Remis RS, Helgerson SD et al. Hemorrhagic colitis associated with a rare Escherichia coli serotype. $N$ Engl J Med 1983; 308: $681-685$.

2. Centers for Disease Control and Prevention. Community outbreak of hemolytic uremic syndrome attributable to Escherichia coli O111:NM - South Australia 1995. MMWR Morb Mortal Wkly Rep 1995; 44: 550-551, 557-558.

3. Pavia AT, Nichols CR, Green DP et al. Hemolytic-uremic syndrome during an outbreak of Escherichia coli $0157: \mathrm{H} 7$ infections in institutions for mentally retarded persons: clinical and epidemiologic observations. $J$ Pediatr 1990; 116: 544-551.

4. Reida P, Wolff M, Pohls HW et al. An outbreak due to enterohaemorrhagic Escherichia coli O157:H7 in a children's day care centre characterized by person-to-person transmission and environmental contamination. Int $J$ Med Microbiol Virol Parasitol Infect Dis 1994; 281: 534-543.

5. Thomas A, Cheasty T, Frost JA, Chart H, Smith HR, Rowe B. Vero cytotoxin-producing Escherichia coli, particularly serogroup O157, associated with human infections in England and Wales: 1992-4. Epidemiol Infect 1996; 117: 1-10.

6. Akashi S, Joh K, Tsuji A et al. A severe outbreak of haemorrhagic colitis and haemolytic uraemic syndrome associated with Escherichia coli $0157: \mathrm{H} 7$ in Japan. Eur $J$ Pediatr 1994; 153: 650-655.

7. Chapman PA, Siddons CA. A comparison of immunomagnetic separation and direct culture for the isolation of verocytotoxinproducing Escherichia coli 0157 from cases of bloody diarrhoea, non-bloody diarrhoea and asymptomatic contacts. $J$ Med Microbiol 1996; 44: 267-271.

8. Belongia EA, MacDonald KL, Parham GL et al. An outbreak of Escherichia coli $\mathrm{O} 157: \mathrm{H} 7$ colitis associated with consumption of precooked meat patties. J Infect Dis 1991; 164: 338-343.

9. Swerdlow DL, Woodruff BA, Brady RC et al. A waterborne outbreak in Missouri of Escherichia coli $\mathrm{O} 157: \mathrm{H} 7$ associated with bloody diarrhea and death. Ann Intern Med 1992; 117: $812-819$.

10. Orr P, Lorencz B, Brown R et al. An outbreak of diarrhea due to verotoxin-producing Escherichia coli in the Canadian Northwest Territories. Scand J Infect Dis 1994; 26: 675-684.

11. Rodrigue $\mathrm{DC}$, Mast $\mathrm{EE}$, Greene $\mathrm{KD}$ et al. A university outbreak of Escherichia coli $0157: \mathrm{H} 7$ infections associated with roast beef and an unusually benign clinical course. $J$ Infect Dis 1995; 172: 1122-1125.

12. Carter AO, Borczyk AA, Carlson JAK et al. A severe outbreak of Escherichia coli O157:H7-associated hemorrhagic colitis in a nursing home. $N$ Engl J Med 1987; 317: 1496-1500.

13. Shefer AM, Koo D, Werner SB et al. A cluster of Escherichia coli $\mathrm{O} 157: \mathrm{H} 7$ infections with the hemolytic-uremic syndrome and death in California. A mandate for improved surveillance. West $J$ Med 1996; 165: 15-19.
14. Ostroff SM, Griffin PM, Tauxe RV et al. A statewide outbreak of Escherichia coli 0157:H7 infections in Washington State. Am J Epidemiol 1990; 132: 239-247.

15. Griffin PM, Ostroff SM, Tauxe RV et al. Illnesses associated with Escherichia coli O157:H7 infections: a broad clinical spectrum. Ann Intern Med 1988; 109: 705-712.

16. Shah S, Hoffman R, Shillam P, Wilson B. Prolonged fecal shedding of Escherichia coli $\mathrm{O} 157: \mathrm{H} 7$ during an outbreak at a day care center. Clin Infect Dis 1996; 23: 835-836.

17. Roberts CL, Mshar PA, Cartter ML et al. The role of heightened surveillance in an outbreak of Escherichia coli O157.H7. Epidemiol Infect 1995; 115: 447-454.

18. McCall B, Strain D, Hills S et al. An outbreak of Escherichia coli 0157 infection on the Gold Coast. Comm Dis Intell 1996; 20: $236-239$.

19. Sramkova L, Bielaszewska M, Janda J Blahova K, Hausner O. Vero cytotoxin-producing strains of Escherichia coli in children with haemolytic uraemic syndrome and diarrhoea in Czechoslovakia. Infection 1990; 18: 204-209.

20. Park $\mathrm{CH}$, Gates KM, Vandel NM, Hixon DL. Isolation of Shiga-like toxin producing Escherichia coli (O157 and nonO157) in a community hospital. Diagn Microbiol Infect Dis 1996; 26: 69-72.

21. Salmon RL, Farrell ID, Hutchison JGP et al. A christening party outbreak of haemorrhagic colitis and haemolytic uraemic syndrome associated with Escherichia coli O157:H7. Epidemiol Infect 1989; 103: 249-254.

22. Centers for Disease Control and Prevention. Lake-associated outbreak of Escherichia coli O157:H7 - Illinois, 1995. MMWR Morb Mortal Wkly Rep 1996; 45: 437-439.

23. Karch H, Janetzki-Mittmann C, Aleksic S, Datz M. Isolation of enterohemorrhagic Escherichia coli O157 strains from patients with hemolytic-uremic syndrome by using immunomagnetic separation, DNA-based methods, and direct culture. J Clin Microbiol 1996; 34: 516-519.

24. Tanaka $\mathrm{H}$, Ohseto $\mathrm{M}$, Yamashita $\mathrm{Y}$ et al. [Bacteriological investigation on an outbreak of acute enteritis associated with verotoxin-producing Escherichia coli $\left(0111: \mathrm{H}^{-}\right.$.] Kansenshogaku Zasshi 1989; 63: 1187-1194.

25. Gunzburg S, Gracey M, Forbes D, Hewitt I, Bettelheim KA Haemolytic-uraemic syndrome and verocytotoxigenic Escherichia coli. Med J Aust 1988; 149: 54--55.

26. Kodoh Y, Kai A. Outbreaks of VTEC infection, 1984-1994. Notiziario Ist Sup Sanità 1995; 8: 2-3.

27. Caprioli A, Luzzi I, Rosmini F et al. Communitywide outbreak of hemolytic-uremic syndrome associated with non-O157 verocytotoxin-producing Escherichia coli. J Infect Dis 1994; 169: $208-211$

28. Capek I, Ilef D. Une singulière épidémie dans l'Oise. Bull Epidemiol Hebdomadaire 1993; 48: 2.21-222.

29. Banatvala N, Debeukelaer MM, Griffin PM et al. Shiga-like toxin-producing Escherichia coli $\mathrm{O} 11 \mathrm{1}$ and associated hemolytic-uremic syndrome: a family outbreak. Pediatr Infect Dis $J$ 1996; 15: 1008-1011.

30. Giles C, Sangster G, Smith J. Epidemic gastro-enteritis of infants in Aberdeen during 1947. Arch Dis Child 1949; 24: 45-53.

31. Belnap WD, O'Donnell JJ. Epidemic gastroenteritis due to Escherichia coli O-111. A review of the literature with the epidemiology, bacteriology, and clinical findings of a large outbreak. J Pediatr 1955; 47: 178-193.

32. Paton AW, Ratcliff RM, Doyle RM et al. Molecular microbiological investigation of an outbreak of hemolytic-uremic syndrome caused by dry fermented sausage contaminated with shiga-like toxin-producing Escherichic coli. J Clin Microbiol 1996; 34: 1622-1627.

33. Goldwater PN, Bettelheim KA. An outbreak of hemolytic uremic syndrome due to Escherichia coli $0157: \mathrm{H}^{-}$: Or was it? Emerg Infect Dis 1996; 2: 72-73.

34. Goldwater PN, Bettelheim KA. The role of enterohaemorrhagic E. coli serotypes other than $\mathrm{O} 157: \mathrm{H} 7$ as causes of disease. In: Karmali MA, Goglio AG (eds) Recent advances in verocytotoxin-producing Escherichia coli infections. (Excerpta Medica International Congress Series 1072). Amsterdam, Elsevier Science. 1994: 57-60.

35. Goldwater PN, Bettelheim KA. The role of enterohaemorrhagic Escherichia coli serotypes other than $0157: \mathrm{H} 7$ as causes of disease in Australia. Commun Dis Intell 1995; 19: 2-4.

36. Wade WG, Thom BT, Evans N. Cytotoxic enteropathogenic Escherichia coli. Lancet 1979; ii: 1235-1236. 
37. Thomas A, Chart H, Cheasty T, Smith HR, Frost JA, Rowe B. Vero cytotoxin-producing Escherichia coli, particularly serogroup 0157 , associated with human infections in the United Kingdom: 1989-91. Epidemiol Infect 1993; 110: 591-600.

38. Bockemühl J, Aleksic S, Karch H. Serological and biochemical properties of Shiga-like toxin (verocytotoxin)-producing strains of Escherichia coli, other than O-group 157, from patients in Germany. Int J Med Microbiol Virol Parasitol Infect Dis 1992; 276: $189-195$.

39. Kudoh Y, Kai A, Obata $\mathrm{H}$ et al. Epidemiological surveys on verocytotoxin-producing Escherichia coli infections in Japan. In: Karmali MA, Goglio AG (eds) Recent advances in verocytotoxin-producing Escherichia coli infections. (Excerpta Medica International Congress Series 1072.) Amsterdam, Elsevier Science. 1994: 53-56.

40. Wilson MW, Bettelheim KA. Cytotoxic Escherichia coli serotypes. Lancet 1980; i: 201.

41. Bielaszewska M, Janda J, Bláhova K, Srámkova L, Havlík J, Potužník V. Verocytotoxin-producing Escherichia coli in children with hemolytic uremic syndrome and diarrhea in the Czech Republic. In: Karmali MA, Goglio AG (eds) Recent advances in verocytotoxin-producing Escherichia coli infections. (Excerpta Medica International Congress Series 1072.) Amsterdam, Elsevier Science. 1994: 37-40.

42. Mariani-Kurkdjian P, Denamur E, Milon A et al. Identification of a clone of Escherichia coli $\mathrm{O} 103: \mathrm{H} 2$ as a potential agent of hemolytic-uremic syndrome in France. J Clin Microbiol 1993; 31: 296-301.

43. Tarr PI, Fouser LS, Stapleton AE et al. Hemolytic-uremic syndrome in a six-year-old girl after a urinary tract infection with Shiga-toxin-producing Escherichia coli O103:H2. N Engl
$J$ Med 1996; 335: 635-638.

44. Anon. Outbreak of acute gastroenteritis attributable to Escherichia coli serotype O104:H21 - Helena, Montana, 1994. JAMA 1995; 274: 529-530.

45. Uchida $\mathrm{H}$, Kanegane $\mathrm{H}$, Yoshiya $\mathrm{K}$ et al. [Four cases of hemolytic uremic syndrome (HUS) associated with serotype O165 verotoxin producing Escherichia coli (VTEC) identified by LPS-solid phase enzyme-linked immunosorbent assay (ELISA)]. Kansenshogaku Zasshi 1995; 69: 678-683.

46. Bitzan $M$, Karch $H$, Maas MG et al. Clinical and genetic aspects of Shiga-like toxin production in traditional enteropathogenic Escherichia coli. Zentralbl Bakteriol 1991; 274: 496-506.

47. Piérard D, Stevens D, Moriau L, Lior H, Lauwers S. Isolation and virulence factors of verocytotoxin-producing Escherichia coli in human stool samples. Clin Microbiol Infect 1997; 3: $531-540$.

48. Karmali MA, Steele BT, Petric M, Lim C. Sporadic cases of haemolytic-uraemic syndrome associated with faecal cytotoxin and cytotoxin-producing Escherichia coli in stools. Lancet $1983 ; 1: 619-620$

49. Centers for Disease Control and Prevention. Summary of notifiable diseases, United States 1995. MMWR Morb Mortal Wkly Rep. 1996; 44: 1-87.

50. World Health Organization. The WHO consultation on the prevention and control of enterohaemorrhagic Escherichia coli (EHEC), Geneva, 28 April-1 May 1997. WHO, Geneva. 1997.

51. Goldwater PN, Bettelhem KA. An unusual anaemia associated with enterohaemorrhagic Escherichia coli O113: H21 infection, a verocytotoxin-2/shiga toxin-2 producing serotype. $J$ Infection 1998 (in press). 